\title{
SOBRE EL MITO DE OSIRIS
}

\section{THE OSIRIS MYTH}

\section{Octavi Piulats Riu ${ }^{1}$ \\ Universidad de Barcelona (España)}

Resumen: El artículo presenta el Mito de Osiris de la antigua cultura egipcia, mito que ciertamente no pertenece a la tradición mitológica asiática, sino a la tradición del llamado "fértil creciente" de Oriente Medio aunque sus raíces son africanas. Justificamos empero su inclusión en esta selección debido a la enorme trascendencia que ha tenido dicho mito en el imaginario religioso europeo y en especial en el de la religión judeo-cristiana. El primer objetivo del artículo es exponer los orígenes y las fuentes de dicho mito. En segundo lugar la intención es exponer un breve resumen de la comprensión del mito en general pero en especial la peculiaridad del mito egipcio. El tercer objetivo del artículo reside en tratar de realizar una interpretación filosófica del mismo, prioritariamente a través de los textos de Plutarco. La tesis final apunta a que se trata de un mito que apoyado en la iniciación práctica, aporta respuestas a algunas de las preguntas existenciales humanas.

Palabras clave: iniciación, magia (heka), conciencia,
espiritualidad

Abstract: This article exposes one of the oldest myths of the mankind, the Myth of Osiris, which certanly does not belongs to the Orient myths- ist roots are in Africa to find-. Nevertheless, the history of Osiris because its great influence in connection with the european religious imaginary, deserves to be included in this selection. The first purpose of the article is to explain the origin of the myth and its sources. The second intention deals with the meaning of the myths in general and about its differents levels of knowledge in the egyptian tradition. The third objective treies to develop the philosophical significance of the subject above all concerning the Plutarc works. The main achievement of the article shows

[1] Profesor Titular en la Universidad de Barcelona. 
that the myth of Osiris has a "initiation" character and leads to some human existential answers

Keywords: initiation, heka (magic), conscience, spirituality

\section{La significación de la mitología}

Ya que vamos a centrar nuestra atención sobre un mito religioso, no es una pérdida de tiempo reflexionar sobre el grado de verdad y confianza que merece esta expresión cultural. En la Modernidad contamos los mitos y leyendas a nuestros niños, para a continuación avisarles que es un producto cultural fantástico, con lo cual estamos aceptando la tesis de A. Comte ${ }^{2}$ cuando señala que las antiguas culturas pertenecen a la etapa infantil de la humanidad. A nivel académico esto se corresponde con lo que el actual positivismo filológico nos dice del mito: "es el resultado de una operación intelectual ingenua y fantasiosa sobre los hechos de la experiencia cósmica o social".

Si queremos disentir de estas concepciones hay que empezar por distinguir entre mito y leyenda. La leyenda o saga suele ser efectivamente una narración imaginativa e ingenua que describe sucesos sorprendentes e incluso paranormales. No obstante la misma suele tener un fondo histórico o geográfico edificado por el imaginario de un pueblo o colectividad. En segundo lugar encontramos el mito, básicamente el mito religioso, que es mucho más complejo. Ya desde la antigüedad han existido múltiples interpretaciones de lo que es un mito. En la Grecia antigua, Evémero presentó la hipótesis que los dioses míticos fueron en realidad reyes ancestrales de los pueblos, posteriormente divinizados por sus súbditos. Así Zeus había sido en origen un antiguo rey de Creta que se levantó contra Cronos en Grecia continental y luego sus hechos fueron divinizados. En el siglo XIX, F. Creuzer fue el primer pensador que interpretó el mito como vehículo simbólico para transmitir fenómenos psíquicos, naturales, históricos e incluso ideas metafísicas. En el siglo XX y ya en el marco de la psicología hamanística y transpersonal el mito fue asociado al inconsciente tanto individual como el colectivo siguiendo las hipótesis de C. G. Jung ${ }^{3}$. De esta forma el mito sería una explicación coherente no sólo de tipologías inconscientes humanas, sino de arquetipos simbólicos que proyectarían invariantes culturales de la humanidad en función de periodos históricos.

[2] Comte. A. Curso de Filosofía Positiva. Madrid Ed. Aguilar. 1973.

[3] Jung. C.G. Los Arquetipos y lo Inconsciente colectivo. Vol 9/1. Madrid. Ed Trotta. 2002. 
No nos resistimos incluso a mencionar (por su gran popularidad) que en el siglo XXI de la mano de autores como el inefable Erich von Däniken ${ }^{4}$, aparece la teoría de que los mitos religiosos han de interpretarse en clave simbólica futura y espacial, ya que reproducen la llegada de los antiguos astronautas alienígenas.

En esta exposición adquiere especial relevancia lo que entendemos por "símbolo", ya que la simbología es el centro de la interpretación mítica. En términos generales lo que denominamos "símbolo" es un intermediario entre nosotros y la realidad natural. De hecho las palabras y la escritura pueden considerarse como símbolos que relacionan la realidad exterior con nuestra subjetividad interior. Ante la complejidad del mundo natural, el simbolismo sirve para acotar y dar significación a una parcela de esta realidad, por esta razón E. Cassirer ${ }^{5}$ señaló el simbolismo como el origen de toda cultura. No obstante en el lenguaje cotidiano moderno lo que designamos normalmente como símbolo no son lenguajes fonéticos y matemáticos, sino un ideograma o dibujo artístico que hace de vehículo significativo entre nosotros y la realidad objetual, aportando una comprensión causal a simple vista no detectable si no se conocen las claves de una determinada tradición. Enfrentados a la significación de un símbolo si no tenemos el bagaje de la tradición que ha creado este símbolo, a pesar de aplicar toda nuestra racionalidad y lógica al mismo restará incomprensible.

Aquí nos adentramos ya en la diferenciación entre el simbolismo exotérico y el simbolismo esotérico. Los símbolos o anagramas exótericos son interpretables (como la ONU) a partir de un conocimiento lógico del lenguaje o de las funciones de los sujetos u objetos del símbolo, en cambio cuando una simbología supera la lógica y el análisis del lenguaje y se sumerge en el ámbito de una tradición desconocida, estamos hablando ya de una simbología "esotérica", que oculta el verdadero significado. La simbología que encontramos en los mitos ancestrales religiosos es de este segundo tipo, lo que implica que para intentar descifrar un mito como el de Osiris, tendremos que dominar la tradición religiosa del país del Nilo.

[4] Cassirer.E. Antropología Filosófica. México F.C.E. 1971.

[5] Däniken. Erich von. Recuerdos del futuro. Barcelona Ed.Plaza \& Janes. 1974. 


\section{El mito de Osiris}

El culto de Osiris se estableció por primera vez en $A b y d o s^{6}$, ya en el primer periodo de las primeras dinastías, aunque posiblemente también existía en Busiris bajo el nombre de Andyeti. Lo cierto es que al final de la IV Dinastía Osiris era ya el principal dios de la región de Abydos, no obstante podemos afirmar que el mito procede de mucho antes probablemente del Egipto pre-dinástico en torno a 3500 años antes de Cristo. Se discute actualmente si es originario de Egipto o fue introducido desde Siria. En algunas tumbas de la IV Dinastía tenemos ya representaciones pictóricas del mito en concreto en una tumba de Saqqarah. Luego el mito lo podemos localizar en los jeroglíficos de los llamados "Textos de los Sarcófagos", y otras exposiciones del mito lo tenemos en la piedra de Shabako y en la estela de Ikhemofret. Y por supuesto parcialmente expuesto en las diferentes viñetas del Libro de los Muertos. Como veremos posteriormente era uno de los nueve dioses primordiales o Enéada de función creacionista y luego se convirtió en rey del inframundo y de la inmortalidad, así como en la representación de la resurrección vegetal. El pez es otro símbolo de Osiris.

Los egipcios representaban a Osiris como una divinidad totalmente antropomórfica y humana con un sudario blanco de momificación o sea siendo un "sajú" la primera momia. Estaba ataviado con una corona troncocónica llamada Atef, franqueada por dos plumas de cuya base partían dos cuernos de carnero retorcidos cuyo significado es desconocido. Blandía los símbolos de la realeza, o sea, dos cayados: el de Heka (magia), y el Uas (poder) así como el mayal, con barba osiriaca siendo su piel de color normalmente verde. Con dicho color se aludía al carácter vegetal de resurrección anual del dios.

Pero debemos ir hasta la XII Dinastía para localizar los misterios de Osiris en representaciones públicas. Las representación del mito de Osiris hasta la Dinastía XII era algo exclusivo de las tumbas del Faraón y personajes de élite, pero como sabemos en esta época tuvo lugar una revolución social y espiritual y los sacerdotes decidieron en un ejercicio de comunismo religioso abrir la significación del mito de Osiris a todas las clases sociales, de forma que incluso las capas más bajas de la sociedad pudieran acceder a la teoría osiriaca de la inmortalidad. A partir de entonces todo finado tuvo acceso al ritual de Osiris y por tanto a algún tipo de momificación y de utilización de los papiros guía para la otra vida.

[6] Mayassis. S. Mystères et Initiations de L'Égipte ancienne. Atenas .Ed. B.A.O.A. 1957. 
En este ensayo voy a priorizar la exposición del mito que hace Plutarco, en su conocido texto "Isis y Osiris" frente a otras fuentes, aunque para la Tanatología osiriaca me centraré básicamente en la información del Libro de los Muertos. Muchos egiptólogos señalan que la versión de Plutarco se halla adulterada por el Helenismo, lo cierto es que por contra hay otros egiptólogos que la prefieren, por el hecho que Plutarco (sacerdote él mismo) es el mayor conocedor en la época helenística de la tradición religiosa egipcia y la información que nos procura es de una persona que se ha sumergido desde el punto de vista espiritual y filosófico en el mito. Además su formación neo-pitagórica le adscribe a la tradición filosófica pitagórica que en gran parte se remite a la religiosidad de Egipto y a sus prácticas de iniciación.

\section{Isis y Osiris}

Plutarco empieza afirmando que Osiris nace de la unión entre Nut la diosa del cielo y Geb el dios de la tierra el primer día de los llamados en Egipto días Epagomenos que completan el año solar. Isis su hermana nació el cuarto día, pero pronto se desató el cariño y luego el amor entre ellos. Plutarco señala que incluso se unieron antes de nacer ambos en el seno de su madre y ya entonces tuvieron el primer hijo, llamado Horus el viejo o también Arueris.

El Creador $R a$ permitió que Osiris reinase al principio, y Osiris como el heleno Prometeo se apiadó de las dificultades de la raza humana, y les enseño las primeras técnicas agrícolas y arquitectónicas, al tiempo que instituía las primeras leyes y sembraba Maat (justicia) en las diversas regiones de Egipto. La música y la danza fueron también creadas pro Osiris, por lo que los griegos-dice Plutarco- asimilan Osiris a Dionisio. Seth el dios del desierto y la guerra, hermano de Osiris tuvo envidia del mismo y preparó una emboscada. Tras conocer sus medidas y como en un juego lo invitó con otros conjurados a que probase de tenderse en un cofre, y cuando Osiris lo hizo Seth sello el cofre con plomo y en el delta del Nilo lanzó a Osiris al mar para consumar su muerte. Isis desesperada empezó a buscar el cuerpo de Osiris por Egipto, en esta búsqueda advirtió que Osiris había tenido equivocadamente una relación con su hermana la diosa Neftis tomándola por ella, y que de esta unión había nacido un niño que más tarde fue el dios Anubis, quien ayudó a Isis a encontrar a Osiris. El féretro de Osiris había llegado por las olas hasta Biblos, en donde creció dentro de un

[7] Plutarco. Isis y Osiris. Barcelona Ed. Obeslisco. 1997. 
árbol gigantesco: un tamarisco. Isis negoció con el rey de Biblos Malcando la entrega del árbol y tras una rocambolesca historia consiguió obtener el féretro de Osiris y llevarlo en una nave hacia Egipto.

Una vez en Egipto, Plutarco nos da una información interesante, indica que primero Isis se apresuró a poner en seguridad al hijo de Osiris y ella: Horus, en la localidad de Bruto, con lo que está indicando que quizás existe un segundo Horus, tras Horus el viejo, o bien debemos entender que el segundo Horus y el primero son lo mismo.

$\mathrm{Al}$ así hacerlo dejó Isis por un tiempo el féretro de Osiris escondido en las marismas y por esta razón por la noche Seth que iba de caza halló el féretro y al ver el cadáver lo descuartizo en 14 pedazos y los escondió en diferentes lugares. Una vez Isis volvió de Bruto, al no hallar el cadáver empezó una larga marcha por todo Egipto para recuperar los trozos de Osiris. Los halló todos y pudo recomponer el cuerpo, menos el pene que fue ingerido por peces, en especial el Oxirrinco. Plutarco no detalla mucho qué hizo Isis-seguramente porque era la parte más conocida del mito-, pero se presupone que momificó el cuerpo de su amado substituyendo luego el falo por una imitación, y con ritual Heka lo preparó para su viaje al Duat, al inframundo. Cuando Osiris atravesó el Duat y salió a la luz del día, apoyó a Horus para que combatiese con Seth. Entre Horus y Seth hubo un primer combate que terminó con la victoria de Horus y con Seth preso y atado, pero Isis permitió que Seth recobrase la libertad, ante el enfado de Horus. Luego tuvo lugar un segundo combate que empezó cuando Seth sugirió que Horus era un hijo bastardo de Isis. En esta segunda lucha el dios Thot intervino a favor de Horus, quien finalmente fue declarado legítimo heredero de Osiris y del reino. El mito acaba con otra sorpresa: Plutarco escribe que Isis y Osiris tuvieron una relación después de que éste descendiera al Duat, e Isis dio a luz un niño: Harpocrátes. Aunque Plutarco no lo aclara, la tradición indica que Harpocrates era Horus como niño. La narración mítica termina con unas palabras de Plutarco sobre el sentido del mito que vale la pena reproducir:

"Y de la misma manera que afirman los matemáticos que el arco iris es imagen del sol diversamente coloreado y matizado por la reflexión de sus rayos en las nubes, el mito que acabo de narrar es la imagen de cierta verdad, que refleja un mismo pensamiento en diversos ambientes, como nos lo dan a entender esos ritos impregnados de luto y tristeza aparente, esas disposiciones arquitectónicas de los templos cuyas diversas partes se desarrollan en libertad..."

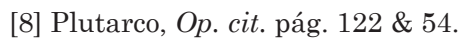


En otras palabras, Plutarco nos transmite la tesis de que la narración mítica sobre la epopeya de Osiris no ha de entenderse de forma literal y subjetiva, sino como una explicación simbólica de profundas verdades metafísicas y antropológicas. Pero también indica que este simbolismo es polimórfico, y que es significativo en diversos contextos religiosos y sociales.

La segunda parte del texto "Isis y Osiris" nos expone las reflexiones de Plutarco sobre el mito de Osiris. Su primer cuidado es refutar al poeta Evémero, quien afirmaba la existencia histórica de los dioses como reyes ancestrales. A este respecto afirma que la naturaleza de estos seres ancestrales remite a los genios, es decir entidades intermedias entre lo divino y lo humano, que aunque tengan el principio divino sus almas no son puras sino en mezcla con lo humano y de estar forma pueden sentir emociones y pasiones. La tesis de Plutarco es afirmar que, con el tiempo, los buenos genios que eran Isis y Osiris una vez purificados acabaron siendo adorados como dioses. En esta misma reflexión se identifica a Isis con las estrella Sirio y a Osiris como la constelación Orión, una vez ascendieron al cielo. Luego Plutarco pasa a señalar que desde otra perspectiva estos genios-dioses incidieron sobre el planeta, y así afirma que muchos aceptan que Osiris es al mismo tiempo el Nilo, y que Isis es la tierra egipcia Kemi (nombre de Egipto en egipcio) y Seth el desierto y el mar. De aquí pasa a exponer otro atributo de Osiris, que es el principio de la humedad y de la germinación vegetal. Posteriormente Plutarco muestra con una serie de correspondencias religiosas y ritualísticas la razón del porqué los griegos identifican a Osiris con Dionisos (a causa de su desmembramiento). Luego Plutarco llega a la comprensión filosófica y en el intento de asignar a Osiris con el bien y a Seth con el mal realiza un excurso por las religiones de persas y griegos, y en algún momento parece aceptar una visión dualista y zoroastriana de la lucha de Osiris y Seth. Pero más adelante recurre para dar una explicación filosófica al Timeo de Platón, distanciándose del maniqueísmo y el gnosticismo y aceptando la suma bondad de lo divino y la relatividad del mal, cuya función es entorpecer pero no vencer a la divinidad.

Finalmente Plutarco se ocupa de Osiris como rey del Duat o inframundo, y lo iguala al griego Plutón o Hades, pero curiosamente dedica muy poco espacio a esta función de Osiris. Aquí Plutarco trata de matizar que las almas de los difuntos en el Duat no participan de Osiris hasta que han sido purificadas y ascienden al éter, es entonces cuando comparten con el Dios su destino. Es posible que Plutarco como neo-pitagórico rechazase la teoría del inframundo bajo tierra, y situase prioritariamente a las almas finadas en su trayecto astral regenerativo hacia el éter y los planetas. 
En consecuencia debemos referirnos ahora a las diversas viñetas y textos del Libro de los Muertos ${ }^{9}$ para completar el mito tal como los egipcios lo concebían. Según los textos, Isis, con su reconstrucción y momificación del cuerpo sin vida de Osiris, consiguió a través de Heka, que algunas partes de la conciencia e identidad de Osiris (el Ka, el Ba, el Akh, y el Ib) no entrasen en confusión y disolución permitiendo que por primera vez Osiris realizase un viaje al inframundo o Duat, y allí tuviese la experiencia de regenerarse y vencer a la muerte en espíritu y posteriormente salir a la luz del día y ascender a las estrellas. Una vez Osiris como Dios espiritual asciende al éter vemos cómo se aparece a Horus su hijo y lo apoya en su intención de convertirse en su sucesor contra Seth. Sin embargo Osiris, en un gesto de amor infinito hacia los humanos, vuelve al Duat y comparte su estancia en los cielos con su reinado ahora en el inframundo, con la misión de acompañar (diga lo que diga Plutarco) a los seres humanos que tras él sufren el fenómeno de la muerte. Básicamente su función será la de presidir el Juicio post-mortem de las almas junto a Thot, Anubis e Isis y Neftis, acompañados de los jueces o ancestros familiares. En este juicio se procederá a la piscostasis o pesada de almas en la balanza de los actos positivos y negativos realizados en vida por el difunto, concretados en su corazón (ib) en función de la diosa Maat u orden cósmico. Según el resultado de la balanza el finado continuará su regeneración en el Duat o será lanzado a los dominios del monstruo Amrit que significa que no atravesará el Duat. Pero lo fundamental es que es Osiris el dios que pronunciará el veredicto.

Para la subjetividad egipcia Osiris era el primer ser que sufría la muerte y sus horrores, pero al mismo tiempo fue capaz, con la ayuda de Isis, de resucitar a la vida, y de esta forma era el guía para los avatares de la muerte para todo egipcio. Para la mentalidad egipcia, la tragedia de Osiris significaba un proceso de identificación con el dios hacia la resurrección en la otra vida. Como divinidad Osiris era inmortal, pero se sometió a la muerte física, para mostrar que tras ésta existe siempre una resurrección. Desde la Modernidad y su orientación según las religiones monoteístas esta resurrección se antoja espiritual, lo que significa una división radical entre cuerpo y alma, pero para la mentalidad egipcia con siete categorías de la conciencia ( Ka, Ba, Khaibit, Ib, Akh, Sehem, Ren) esta idea era anacrónica.

Debemos no obstante volver por último a Plutarco para tratar de clarificar tanto la misteriosa mención de tres configuraciones del dios Horus. El llamado Horus el Viejo, o Aureis, concebido antes del nacimiento de sus padres, simboliza la materia que sale de la diosa Nut; es el primer

[9] Barguet.P. El Libro de los Muertos. Bilbao Ed. Desclée de Brouwer. 2000. 
parto de la Naturaleza imperfecta, pero ya dispuesta a recibir los efluvios de su padre Osiris, o sea, la inteligencia creadora. El Horus intermedio es el hijo legítimo de Osiris e Isis, pero es partícipe tanto de la materia como del espíritu, mientras que el Horus Harpócrates, concebido post-mortem, es espíritu puro, triunfo de la resurrección. Los tres nombres son el mismo Horus, el principio del mundo que se regenera constantemente y que siempre triunfa ante el desorden o Seth.

\section{La peculiaridad del mito egipcio}

La exposición del mito de Osiris que hace Plutarco, pero también el mito osiriaco según otras fuentes, en un primer momento puede desconcertar al lector, ya que más allá del simbolismo esotérico, las diversas funciones y significaciones de Osiris son múltiples y a veces contradictorias entre sí, de forma que desde una posición racional y lógica es muy difícil su significación. Para llevar a cabo una interpretación coherente debemos exponer en primer lugar el concepto de divinidad en la tradición egipcia, y luego reconstruir la peculiaridad cognitiva del mito egipcio comparando a menudo su estructura con la conocida mitología helena.

La palabra que define a la divinidad en el país del Nilo es "ntr" que transliterado lo traducimos con vocales como "netjer". Es probable que su origen se halle en el totemismo africano, pero luego netjer evolucionó hacia un antropomorfismo sin dejar de perder algunos rasgos totémicos y zoológicos.

Una gran parte de los egiptólogos modernos, como E. Hornung ${ }^{10}$ o H. Frankfort o el mismo Christian Jacq, pero también espiritualistas como Schwaller de Lubicz ${ }^{11}$ sostienen la tesis de que los egipcios no practicaban el animismo, ni un politeísmo, ni por supuesto un monoteísmo, (al menos hasta Akhenaton, el faraón hereje); sino que la religión egipcia, por su componente africano, se basaba en la peculiaridad religiosa del "Henoteismo"; término que se retrotrae al filósofo Schelling, y que modernamente significa que los egipcios adoraban y rendían culto a una divinidad que siendo Uno continuaba siendo al mismo tiempo Múltiple y se desplegaba sin contradicción en numerosas formas.

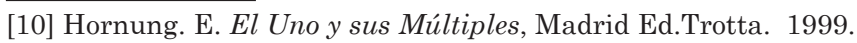

[11] Schwaller de Lubicz, R.A. Le Roi de la Théocratie Pharaonique. Paris. Ed Flammarion. 1950. 
Cuando el egipcio rezaba a sus dioses locales, estos dioses estaban conectados a la vez con Autum-Ra, es decir con el creador o fuente de divinidad primigenia. Por otra parte diversos egiptólogos modernos tienden a ver en los Neteru (plural de nrt), no a dioses en sentido moderno, sino más bien "categorías cosmológicas" de la Naturaleza, es decir, como fuente de vida, poder y realidad, que correspondían de hecho al término griego "Physis", ya que en el antiguo Egipto no existía un término conciso para designar ni la religión ni la naturaleza. De hecho en el lenguaje jeroglífico una aproximación a nuestro concepto de religión lo constituye el término arcaico "Hikew"12 que se traduce como virtud o causalidad no natural o extraordinaria, y engloba al mismo tiempo la significación de religión y magia.

El mito egipcio religioso comparte con los mitos de otras culturas occidentales y orientales una función metodológica de carácter simbólico. Todo mito realiza una narración casi siempre poética en la que se explica la génesis, la causalidad y la identidad de lo existente en la Naturaleza y en el ser humano. Pero esta explicación o corpus mítico se lleva a cabo a través de categorías religiosas intermediarias que actúan como símbolos de esta causalidad y génesis. Sin embargo, posee una dimensión esotérica en el sentido de que la interpretación del símbolo se halla oculta al lego, y para interpretarla debe estar en posesión de una tradición cultural elitista. O dicho de otra forma: todo mito religioso posee dos niveles de significación, el puramente narrativo y artístico y el simbólico que nos conecta con diversos niveles interpretativos.

En un principio el mito egipcio sigue el canon de otras tradiciones en cuanto al simbolismo, pero a diferencia de otras tradiciones míticas, los niveles de comprensión a las que apela el mito egipcio son extremadamente ricos y complejos, de forma que para captarlos, aparte de conocer su tradición, es necesario abandonar los principios lógicos clásicos (contradicción, identidad y causalidad) e ir más allá de ellos sin renunciar a la coherencia.

En primer lugar en mitos egipcios como los de la Creación existe un simbolismo de carácter naturalista. La creación del cosmos, y las categorías astrales, planetarias y geográficas se expresan como hemos dicho a través de lo que la tradición egipcia denomina "neteru", es decir dioses, que podríamos traducir en la mentalidad moderna como "funciones cósmicas". Autum-Ra es el sol, Geb la tierra, Nut el cielo, Isis la estrella Siria, Osiris la constelación de Orión, Seth el desierto y así sucesivamente. Las diversas escuelas teológicas egipcias exponen la génesis del cosmos a tra-

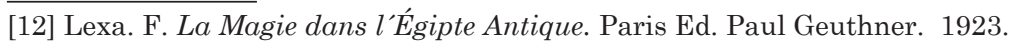


vés de relaciones familiares entre los dioses de la Enéada (los nueve dioses primordiales), sus conflictos emocionales y sus relaciones sexuales, que muestran una primera explicación natural de lo existente. Este primer nivel de carácter naturalista es plenamente compartido por el mito griego. Sólo hay que aludir a la Teogonía de Hesíodo para ver las concomitancias.

En segundo lugar encontramos el nivel histórico del mito, que atañe a la historia tanto sagrada como profana de la humanidad. Por ejemplo en el mito de la "Cólera de $R a$ " se nos explica la existencia de un pasado paradisíaco de la humanidad antes de su caída en la traición, o en el mito del primer reinado de Osiris se nos expone cómo este dios al estilo del Prometeo heleno entrega a los humanos las primeras artes y la técnica. Estos mitos que escenifican la existencia de un "tiempo primero" nos transmiten de forma histórica las causas de las sociedades y de los conflictos humanos. El mito arcaico griego comparte asimismo esta dimensión de simbolismo histórico. En los mitos de la Edad de Oro, la era de los Titanes, o la llegada de Prometeo y Pandora podemos encontrar muchas similitudes, al igual que en la tradición judeo-cristiana con su descripción mítica del paraíso.

En tercer lugar nos encontramos con el nivel psico-social del mito egipcio. Diversos dioses egipcios simbolizan asimismo cualidades psicológicas humanas e incluso aspectos socio-culturales. La diosa Isis al mismo tiempo que se identifica con la estrella Sirio simboliza también el arquetipo de la madre original y de la inteligencia mágica femenina. El dios Osiris aparte de identificarse con la constelación de Orión, se identifica con el Nilo, con el crecimiento vegetal, y como maestro del ser humano en tiempos remotos constituye asimismo el principio paterno original y el símbolo de la resurrección del alma humana. El dios Thot aparte de ser un dios lunar, se constituye como el dios de la sabiduría, de la escritura y de Heka (magia). Esta dimensión psico-social del mito también la hallamos en el mito griego: Afrodita, aparte de identificarse con el planeta Venus, simboliza la belleza y la sensualidad femenina, y Marte la violencia y la guerra, y el mismo Dionisios (que los griegos identifican con Osiris) asume el simbolismo de la resurrección del alma humana y su afán de inmortalidad.

En cuarto lugar el mito egipcio posee un nivel socio-político. En Egipto el Faraón se identificaba místicamente con los dioses de la Enéada que en un pasado remoto habían fundado el país del Nilo. Al mismo tiempo los dioses egipcios obtuvieron una conexión directa con las ciudades en donde se les rendía culto. Ejemplos como Ptah que se convirtió en el dios local de Menfis, o Thot que era el dios de culto en Hermópolis, o el mismo $R a$ en Heliepolis lo atestiguan. Esta conexión de divinidades nacionales con las ciudades y su eticidad ligada a fiestas y costumbres la encontramos 
también en el mundo griego. Basta señalar el caso de Athenea con la ciudad de Atenas, fundamento de su eticidad y su nacionalismo.

En quinto lugar aparece en el mito egipcio el nivel metafísico. Entendemos aquí el término "metafísica" en su primera acepción básica, es decir, como un fundamento de lo visible y concreto que a simple vista no se localiza en la naturaleza visible, pero que constituye la causalidad inmanente de lo natural, y por tanto la trasciende. Bajo el ropaje teológico, el mito egipcio de la creación aborda el problema metafísico de la relación entre lo Uno y lo Múltiple, el tema estrella del diálogo "Parménides" de Platón. En la teología de Hermópolis por ejemplo se explica la transición del ser al no-ser, otro gran problema metafísico. Si ahora comparamos la metafísica oculta en los mitos griegos como en la Teogonía de Hesíodo o el mito de Orfeo sobre la creación del cosmos, advertiremos que el mito egipcio contiene muchas más nociones metafísicas que los mitos creacionistas griegos. Categorías metafísicas como el tiempo, el espacio, la vida, el espíritu, la justicia (Maat) y la dialéctica entre identidad y dualidad son explicadas y presentadas por primera vez de una forma coherente. La noción estrictamente racional de "arché" de los Presocráticos aparece desde la metafísica de la sophia egipcia, un intento juvenil de explicar el origen del cosmos. De hecho tendremos que esperar al Timeo de Platón para volver a encontrar los grandes temas metafísicos (como el Demiurgo) que allí se exponen.

En sexto lugar el mito egipcio muestra una dimensión "energética". Para captar este nivel debemos referirnos al término egipcio "hk3" (transliterado se traduce como Heka) que en muchas obras es traducido como "magia". El problema es que la noción de magia posee ya en origen una connotación negativa para la Modernidad. El concepto "magia" proviene del griego "mageia", que a su vez pudo proceder de los magos persas, o sea "magou", que connota un sentido peyorativo negativo y que apunta a hechicería o brujería. El mismo verbo heleno "magganeuo" significa también engañar. Y muchos autores griegos, como Heráclito, Eurípides o Sófocles critican la magia como actividad engañosa. La antropología moderna y el mismo psicoanálisis adoptan una posición negativa con respecto a este término y definen el pensamiento mágico como una etapa ingenua e infantil de la humanidad. También una gran parte de los egiptólogos dejan de lado el ocuparse seriamente de la magia egipcia y cuando lo hacen continúan atrapados en la noción de brujería moderna. Por esta razón a partir de ahora no utilizaremos la palabra magia sino su concepto egipcio de Heka. Para la mentalidad egipcia Heka era el máximo conocimiento de su cultura, que culminaba los conocimientos empíricos y racionales, y consistía en 
un método para orientar y dominar las energías sutiles e invisibles de la naturaleza a través de los dioses como símbolos mediadores. Ciertamente que ya en Egipto Heka abarcaba fenómenos paranormales tales como la hipnosis, la predicción, la telepatía, la imposición curativa de manos, el sonambulismo, apariciones, sortilegios y alteraciones de conciencia, pero también transmisión de energía psíquica de un Sujeto a un Objeto e interpretación de lo onírico. Es cierto que en estos fenómenos debía incluirse la hechicería, pero precisamente en la época de las grandes dinastías se perseguía la incorrecta utilización de este poder como brujería, y tan sólo a partir de la época Saita encontramos una degeneración del mismo hacia la mera hechicería.

Cuando señalamos, pues, que el mito egipcio posee un nivel energético o de Heka, estamos indicando que el egipcio creía firmemente conectar a través de su conciencia con la estructura energética del mundo circundante, sutil y casi siempre invisible. Los dioses eran el símbolo de conexión entre su conciencia y la realidad tanto la visible como la invisible. Por este motivo mitos como el de Osiris, cuando eran asumidos e interiorizados a través de los rituales, poseían asimismo este nivel mental de conexión de los familiares del finado a través de los dioses con el alma (Ba, Ka)) de la persona que iniciaba su viaje al inframundo (Duat). Esta dimensión "energética" y bio-psíquica no es recogida de forma explícita por el mito heleno; sólo empezará a ser introducida en la Grecia continental a través de la religión de los misterios, que precisamente proviene en sus rituales del área de influencia oriental y específicamente egipcia.

En séptimo lugar, el mito egipcio posee un nivel "iniciático" con su correlato de espiritualidad religiosa. En la cultura egipcia todo fenómeno religioso-mistérico, a nivel sacerdotal y de élites implicaba una vía iniciática. La vía para adentrarse y vivenciar los misterios de dioses y de la naturaleza se denominaba en Egipto "iniciación" (bs) que implicaba una alta esfera de emocionalidad, vivencia energética, y espiritualidad. Este nivel no se hallaba al alcance del pueblo llano, que sólo conocía los ritos exotéricos de las festividades egipcias. Este nivel estaba reservado a un determinado público realista y elitista que a través de la vivencia iniciática del mito debía pasar determinadas pruebas emocionales y espirituales. La comprensión integral de un mito como el de la Creación o el de Osiris, consistía en que el iniciado vivenciase en una representación psico-dramática y casi teatral las categorías expresadas en el mito. A través de una vivencia emocional y espiritual, el iniciado en los misterios de los mitos tenía una comprensión de los mismos y de su significación que superaba la mera 
comprensión intelectual. Consistía en una odisea personal religiosa que le abría la puerta a una apropiación integral de las categorías metafísicas de la narración religiosa. En Grecia hallamos también rasgos de la iniciación en cultos como los de Eleusis, pero de nuevo todo apunta que estos cultos de la Religión de los Misterios procedían de Oriente.

La pregunta que viene a continuación reza ¿cómo hemos de entender desde el pensamiento moderno de carácter lógico-racional estos diversos niveles de simbolismo del mito egipcio y, sobre todo, cómo se interrelacionan los diversos niveles? La respuesta a esta pregunta que ha intrigado a muchos egiptólogos puede tener una respuesta doble. Por un lado el simbolismo cognitivo que aplicaban los egipcios a sus mitos era de carácter circunvalatorio. Es decir un mismo mito podía tener diversos sentidos de significación simultáneos o yuxtapuestos sin que por ello se resintiese su comprensión.

Pero esta comprensión circunvalatoria del simbolismo sólo es posible si aceptamos la tesis de que el modelo de pensamiento egipcio era diferente del griego o del moderno, en el sentido de que su conciencia era visionaria y su lógica polisémica. El adjetivo "visionario" significa, en un contexto africano, que la mentalidad egipcia percibía aspectos sutiles de la Naturaleza de forma intuitiva, como el tema "energético" que antes hemos mencionado, que propulsaban hacia la creencia en una realidad oculta dominada por los dioses. Respecto a la lógica polisémica significa que su patrón cognitivo no aplicaba de forma radical los principios lógicos tradicionales, de no-contradicción, identidad y causalidad, sino que podía trascenderlos. Es decir, en aras de la dimensión visionaria la mentalidad egipcia estaba dispuesta a creer que un fenómeno podía ser y no-ser en el mismo tiempo y espacio. Esto no significaba irracionalidad ni comprensión pre-lógica o ingenua de la realidad, sino más bien una posición que se suele denominar trans-lógica. En este sentido algunos egiptólogos comparan esta visión con la del principio de indeterminibilidad de la física cuántica moderna ${ }^{13}$. En su vida cotidiana el egipcio aplicaba una comprensión racional y lógica de la realidad, pero en lo concerniente a la aceptación de una dimensión invisible de la Naturaleza podía trascender lo lógico.

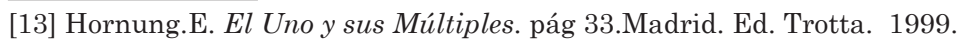




\section{La interpretacion filosófica del mito}

No vamos a entrar aquí en el análisis filosófico de F. W. J Schelling en su filosofía de la Mitología ${ }^{14}$ respecto al mito de Osiris; sólo señalamos que dicho mito adquiere para Schelling una gran relevancia, ya que en el debate sobre Dionisios anticipa la potencia del redentor que luego aparecerá en el Cristianismo.

Existen dos grandes mitos en la religión y la sophia egipcia, el de la creación y el de Osiris. El mito de Osiris que nos ocupa, es el gran mito antropológico de aquella cultura. O dicho en otras palabras, Osiris simbólicamente representa el alma humana en su trayectoria de lo terrenal a lo post mortem.

He aquí un texto de Plutarco que nos conduce a esta tesis junto a una interpretación filosófica y al mismo tiempo platónica del tema:

"No debe considerarse despropósito que los egipcios sostengan que el alma de Osiris es eterna e incorruptible, que su cuerpo sea despedazado varias veces por Seth y que Isis, errante por todo lugar, lo busque y llegue a recomponerlo. Efectivamente, el Ser que es también la inteligencia y el bien, es superior a toda corrupción y a todo cambio. De él se desprenden las imágenes modelo en la materia corpórea y sensible, ella es la que recibe determinantes formas y parecidos, de la misma manera que la cera recibe la huella del sello. Pero las huellas no son eternas. Son aprisionadas por el principio desordenado y tumultuoso que, relegado en este mundo lejos de las regiones excelsas, lucha contra Horus, contra este Dios engendrado por Isis, para que sea imagen sensible del mundo inteligible."15

Se dice, pues, que Seth acusa a Horus de ser hijo bastardo, porque no es puro ni sin mezcla, como su padre, la divina razón, cuya sustancia es esencialmente simple e incapaz de toda pasividad, mientras que él, por su entrada en el mundo corporal, ha sido corrompido por la materia. Pero Horus triunfa saliendo victorioso de esta acusación con ayuda de Thot, es decir de la inteligencia, que prueba que la naturaleza al transformarse reproduce el mundo a imagen del orden inteligible."

[14] Schelling. F.W,J. Urfassung der Philosophie der Offenbarung pág. 337. Hamburg F.Meiner. 2017.

[15] Plutarco. Op.cit. \& 54. 
Aunque Plutarco se muestre cuidadoso al interpretar el mito, ya que trata de traducirlo a la filosofía platónica, lo cierto es que apunta claramente a Osiris como simbolizando el destino del alma humana post-mortem. De la misma manera que Osiris, el ser humano se halla desconcertado e impotente ante el fenómeno de la muerte. Pero, como Osiris, el ser humano posee una parte conciencial divina no corruptible que permanece post-mortem, esa permanencia se hace posible por Isis. La diosa de la Enéada simboliza aquí, por un lado una unidad con Osiris, su hermano; es el principio femenino de la conciencia divina humana, la parte inmortal que es capaz de reagruparse por sí misma. Por otra parte, como diosa es la señora de Heka, es la parte capaz de asumir la momificación y los rituales de evolución de la conciencia post-mortem que reagrupan la identidad humana. Los trozos de Osiris tienen correspondencia simbólica con las puertas que la conciencia debe superar en el Duat.

El engendramiento de Horus-Harpocrates, como hijo póstumo de Osiris, también posee un doble significado: en el escenario del estado faraónico simboliza la continuidad de la realeza del padre hacia el hijo y la superación de la muerte paterna frente al caos. Por otro lado, la figura de Horus, como se insinúa en la cita, simboliza la resurrección del alma humana que ha conseguido regenerarse éticamente y ha mantenido su identidad aunque aparezca bajo otra forma. De aquí que en el texto Plutarco señale la objeción de Seth contra Horus, indicando que es bastardo, que su divinidad no es absoluta. Horus es noble e inmaculado, el Osiris resucitado, pero por su vuelta a la tierra vuelve a contactar con lo sensible y corporal y se expone a nuevas contradicciones. 


\section{Conclusiones}

Por tanto, el miro de Osiris posee una doble significación a nivel global: el mito expresa la posición egipcia frente al fenómeno de la muerte, y lo decisivo que es para que el difunto evolucione en el Duat, el ritual funerario. En una segunda línea interpretativa, el drama de Osiris representa la conciencia individual humana, la triada Osiris-Isis-Horus simboliza en el criterio circunvalatorio los estados diversos por los que atraviesa la conciencia humana. Un ser humano que en su fase Osiriaca muere frente a la negatividad y el mal cósmico y penetra en el mundo de la corrupción corporal y la confusión de la conciencia, pero que en su fase Isiaca es capaz de regenerarse y purificarse, de forma que se emancipa de las adherencias y de la influencia del mal Stehiano; y que, finalmente, en su fase de Horus puede resucitar o bien bajo otra nueva forma o como espíritu (Akh) puro.

Una de las claves finales del mito se centra en el detalle de la desaparición del falo de Osiris que Isis no encuentra. Y a pesar de la falta de esta capacidad sexual reproductiva Isis es capaz de quedar embarazada de Horus niño, el Harpócrates. El simbolismo de la falta del falo alude directamente a que el nacimiento de Horus no es material, sino que tendrá un carácter espiritual.

O dicho ahora en términos filosóficos: el mito de Osiris muestra algo unitario que al mismo tiempo es múltiple. Son tres hipóstasis en una, que nos recuerda a la Trinidad. El alma humana es el objeto más luminoso de la creación, es eterna en sí misma. Osiris en su cofre y en su desmembramiento representa el alma encarnada en su descenso material; empero, para realizar su ciclo y hacer frente a la muerte, necesita de su parte divina y regeneradora, que es Isis; y a fin de resucitar necesita de la esencia del hijo de Horus en una nueva existencia ahora espiritual. Como indica Damascio ${ }^{16}$ el sentido oculto del mito de Osiris, es la evolución de las almas, y su tendencia a unirse con lo divino. Por último, iniciarse en el mito de Osiris significa experimentar por el iniciado la epopeya del dios que sufrió, murió y resucitó. Posiblemente en Abydos se realizase esta iniciación que en principio estaba reservada a pocas personas. Los aspirantes a la iniciación, situados en templos subterráneos que simbolizaban el Duat, vivenciaban parte de la experiencia del dios. Aparte del ayuno, vivían como "saju" un tiempo, para después realizar la confesión negativa, es decir imitar el juicio de Osiris, que les transformaba interiormente y

[16] Mayassis S. Op.cit. "Sobre Damascio" Pág 37.. 
que les conduciría al cabo de un tiempo a la resurrección espiritual en la misma vida terrenal.

Es cierto que el mito de una divinidad que se sacrifica por un acto de amor hacia la Humanidad y atraviesa el umbral de la muerte para resucitar y marcar la senda histórica del género humano constituye una epopeya que se puede encontrar en algunas culturas, como es el caso del dios Tammuz en la cultura mesopotámica, o el mismo Baal en Canán. Pero el hecho de que este mito nos transmita con detalles espirituales una pasión, una muerte y una resurrección de una divinidad lo aproxima mucho más que otros mitos a la cultura judeo-cristiana. No es objetivo de este ensayo establecer correspondencias entre la epopeya de Jesús y la de Osiris, pero sí mencionaremos sucintamente que existen muchos puntos de identificación si recordamos un cuento egipcio como el de Satmi, en el que se expone que la mujer de Satmi, o sea, Mahituaskhit, concebirá un niño que se llamará Senosiris, el cual hará grandes prodigios. O recordamos textos de evangelios apócrifos en donde se nos informa que Jesús viajó tras su muerte física en la cruz a los infiernos para liberar a las almas humanas. $\mathrm{O}$ incluso que uno de los símbolos osiríacos sea el pez. No obstante, la mayor identificación tiene lugar en el hecho que tanto Osiris como Jesús son hijos de la divinidad creadora ancestral y viven su epopeya como una divinidad que se hizo humano para la salvación de la humanidad. 


\section{Bibliografía sucinta}

Assmann J. Ägyptische Mysterien Wilhem Fink Verlag. München 2002.

Barguet.P. El Libro de los Muertos. Ed Desclée de Brouwer. Bilbao 2000 .

Frankfort H. Reyes y Dioses. Ed. Alianza. Madrid 1976

Guilmot M. Les Rites initiatiques en Egypte ancienne. Ed. R. Laffont. Paris 1977.

Hornung. E. El Uno y sus Múltiples. Ed. Trotta.Madrid 1999

Jamblico. Sobre los misterios egipcios. Ed Gredos. Madrid 1997

Kolpaktchy.G. Das Aegyptsche Totenbuch. Ed. Otto Wilhem Barth. München 1955.

Lara peinado. F. El Egipto Faraónico. Ed. Istmo. Madrid 1991

Martin Valentin. F.J. Los magos del antiguo Egipto. Ed. Oberon. Madrid 2002.

Mayassis. S. Mystères et Initiations de L'Égipte ancienne. Ed. B.A.O.A Atenas 1957.

Naydler. J. El templo del cosmos. Ed. Siruela. Madrid 2003.

Plutarco. Isis y Osiris. Ed. Obelisco. Barcelona, 1997.

Schwaler de Lubicz Le Roi de la Théocratie Pharaonique. Paris. Flammarion, 1950. 